\title{
JESÚS, EL JUDÍO DE GALILEA, ¿ERA UN LAICO?
}

Jesus, the Jew from Galilee, Was He a Layman?

Adrián Tolentino García

adtolentino@outlook.com

Universidad Iberoamericana - Ciudad de México - México

\section{Resumen}

El libro recientemente publicado, titulado Un solo corpo: Laicità e sacerdozio nel cristianesimo delle origini, de Romano Penna, defiende la tesis de que Jesús y los primeros cristianos eran laicos. En este ensayo, se reseña los argumentos del autor y se elabora una crítica de sus postulados. La "laicidad" es un anacronismo difícilmente compatible con el siglo I d.C. El cristianismo primitivo se explicaría mejor desde conceptos más justos con la cosmovisión del Judaísmo del Segundo Templo.

Palabras clave: Judaísmo antiguo; judeocristianos; Qumrán; Segundo Templo; secularismo; Modernidad; religión.

\section{Abstract}

The recently published book Un solo corpo: Laicità e sacerdozio nel cristianesimo delle origini, authored by Romano Penna, maintains that Jesus and the first Christians were laypeople. In this essay, the contents of the book are reviewed and criticized. The concept of "laity" is an anachronism roughly compatible with the first century AD. Ancient Christianity would be explained accurately with concepts closer to the Second Temple Judaism worldview.

Keywords: Judaism; Jewish Christians; Qumran; Second Temple; Secularism; Modernity; Religion. 
En su devoción por los "hechos", el erudito recoge los elementos necesarios para la investigación, pero están enmarcados y movilizados desde un "orden" del saber que él desconoce y que funciona sin su conocimiento.

Michel de Certeau (2016: 148).

Romano Penna, Un solo corpo: Laicità e sacerdozio nel cristianesimo delle origini, Roma, Carocci, 2020, 247pp.

Romano Penna, prelado y catedrático de la Universidad Lateranense, en su nuevo libro lleva a cabo una observación de los tiempos primitivos del cristianismo. El escrito parte de la distinción entre laicos y sacerdotes. El autor intentará ofrecer una visión distinta sobre esos tiempos a través de semejante distinción.

Monseñor Penna inaugura su observación con una clarificación de los conceptos de "laicidad" y "religión". La secularización Penna la entenderá como sinónimo de "laicización", que él define como la acentuación de lo laico, o profano, por encima de lo religioso, o confesional. Penna añade que la laicización era ya un fenómeno conocido en el mundo grecorromano. Para comprobarlo, el autor transcribe citas de Varrón, Juvenal y Luciano de Samosata donde se lamenta que el culto a los dioses ya no era el mismo que en tiempos anteriores (p. 12). Sin embargo, Penna previene que el concepto de "laicidad" es uno "sustancialmente moderno" ( $p$. 13). Con esto, se evidencia que el estudio se valdrá de un anacronismo.

Penna continúa con su clarificación de conceptos, esta vez con el de "religión". Se desarrolla la idea de que el vocablo es de estirpe latina — viene de religio- y no tiene equivalente en griego, ni en hebreo. Por eso, denominar como religio al cristianismo fue un hecho tardío. Tácito, Plinio el Joven y Suetonio atacaron la creencia cristiana al calificarla como superstitio. Tertuliano, en apología de la creencia cristiana, la llamará religio. Pero Penna hace bien en matizar que Tertuliano usa el vocablo religio para designar "un hecho de conocimiento intelectual y de veneración cultual" (p. 20). La primera vez que se usa el término religio christiana será en el siglo IV, en los escritos paganos de Arnobio. Sólo a partir de ese momento, se empezará a aplicar el concepto de "religión" al cristianismo. En el principio, sin embargo, el cristianismo no era una religión. 
Esa última afirmación representa la premisa necesaria para formar el juicio central de todo el estudio: "desde el punto de vista sociorreligioso", dice Romano Penna, "Jesús era un laico como lo eran todos los apóstoles y los responsables de las primeras comunidades cristianas". Y, añade Penna, "si en los siglos sucesivos las cosas tomaron un rumbo diferente [...] esto dependió de otros factores que [...] estuvieron más allá de la estructura original" (p. 13). Así, Penna postula que el cristianismo no surgió como una religión, sino como una "fe" de laicos. La religión, por un lado, "representa un intento de ascender hacia Dios [...] a través de una realización compleja autónoma de gestos, ritos, momentos, fórmulas". El cristianismo, por otro lado, es una "adhesión simple y personal a una iniciativa que viene de arriba, de Dios mismo, que, eludiendo las construcciones ceremoniales humanas, se revela inesperadamente en la modesta historia del nazareno Jesús, a quien se dirige el mismo acto de adhesión fiducial" (p. 22).

El segundo capítulo se titula "El sacerdocio en el ámbito grecorromano y hebreo". Penna adopta la acepción corriente de "sacerdote" como mediador entre dioses y humanos. En el mundo griego, el vocablo para designar este oficio es hiereús. Los sacerdotes griegos custodian los templos, preservan las estatuas y hacen sacrificios. En la religión romana la estructura es semejante, pero incluye la veneración de ancestros y de la patria. Entre los romanos había estamentos, empezando por el Pontifex maximus y el Rex sacrorum, pasando por los Flamines (que se consagraban a divinidades particulares), las seis Vestales, los Augures (que interpretaban las constelaciones celestes) y los Quindecemviri, los quince varones (quienes conservaban los Libros Sibilinos).

El Judaísmo, nos recuerda Penna, despuntaba entre los pueblos mediterráneos por la devoción al Templo, la idea de su pertenencia al Pueblo de Dios y la observancia de la Torá. Los sacerdotes se dedican a los sacrificios en el Templo. Sobresale, entre ellos, el Sumo Sacerdote. Entre las funciones de los sacerdotes del Templo estaban los ritos de expiación, como los de Yom Kippur, y las bendiciones públicas. Había también levitas, quienes no gozaban de las mismas prerrogativas que los sacerdotes, como ingresar al altar o al Tabernáculo. Los levitas, en cambio, fungían como músicos, cantores, porteros y vigilantes. Penna se remite al libro de Números $(1: 50-53 ; 3: 5-13 ; 4: 5-15 ; 18: 1-7)$ para verificar sus afirmaciones. 
Después de describir estos pormenores bien conocidos, el autor dirige su atención a lo que él considera la antítesis de los sacerdotes: los laicos. Se elabora una somera revisión del vocablo griego laikós. Dicho término, por supuesto, no tenía la misma acepción que hoy tiene. Derivado del sustantivo laós ("pueblo") el vocablo laikós en la literatura griega no quería designar otra cosa sino aquello perteneciente al pueblo. En las traducciones griegas de la Biblia Hebrea de Áquila, Símaco y Teodoción aparece laikós como traducción del vocablo hebreo hol (זל) en 1Sam 21:5; Ez 22:16 y 48:15. Penna traduce el hebreo hol como "profano". "En cualquier caso, la distinción fundamental [...] no es tanto la diferenciación entre sacerdote y laico, cuanto aquélla entre sacro y profano, correspondiente, respectivamente [sic], a la de impuro y puro" (p. 44). Todo lo anterior le sirve al autor para asegurar que, en el mundo antiguo, había una clara separación entre sacerdotes y no sacerdotes.

Las caracterizaciones precedentes conducen al tercer capítulo: "La laicidad del cristianismo naciente". El autor cree que el cristianismo tuvo dos nacimientos, uno "histórico" y otro "místico". El primero Penna lo ubica en la predicación de Jesús sobre la Basileía, que él traduce como "reino-realeza" (p. 53). El segundo lo ubica en la predicación de los apóstoles de Jesús sobre la resurrección. Ambos inicios, dice Penna, tuvieron una "dimensión laica" (p. 55).

¿Cómo argumenta el autor su juicio? Dice que Jesús fue, ante todo, un laico por los siguientes motivos: (1) porque, étnicamente, los evangelios de Mateo y de Lucas lo presentan como vástago de la tribu de Judá, la cual no era tribu de sacerdotes; (2) porque no respetaba, con rigor, los preceptos de pureza; (3) porque no frecuentaba el Templo; (4) porque se relacionaba igualitariamente con mujeres; (5) porque mantenía distancia respecto a los saduceos y los sacerdotes; (6) porque, cuando dijo que las cosas del César y las cosas de Dios eran diferentes, reconocía "la laicidad de la política" (p. 59) y (7) porque, al expulsar a los mercaderes del Templo, criticó desde fuera —o desde abajo - a la casta sacerdotal.

Por su parte, el inicio "apostólico" del cristianismo fue también laico por motivos muy semejantes. Penna se remite a los Hechos de los Apóstoles y a las Epístolas de Pablo para desarrollar su argumento. El autor señala, en primer lugar, los consabidos datos de que los apóstoles eran pescadores y de que Pablo era constructor de tiendas. Luego, se recoge las caracterizaciones que hace Pablo de los 


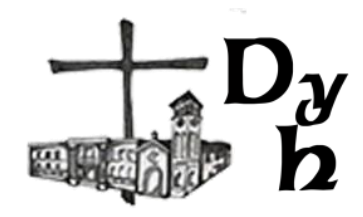

creyentes en Cristo como "los santos" ${ }^{1}$. El autor demuestra que esta santidad poco tiene que ver con el lenguaje ritual, o el legal, del Judaísmo. Esto es indicio de una "santidad laica" que se basa "sobre nada más que la fe y el bautismo" (p. 63).

En seguida, el autor procede a estudiar la estructura de la comunidad cristiana de Jerusalén. Santiago, el hermano de Jesús, encabezaba la comunidad de cristianos establecida en la Ciudad Santa. Penna asevera, con base en los Hechos de los Apóstoles, que la Iglesia era coordinada desde una organización muy parecida al Sanedrín. Esto es prueba de que, como el Sanedrín judío no estaba compuesto por sacerdotes sino por ancianos aristócratas, la estructura de la Iglesia jerosolimitana también era laica.

Este último asunto conduce a la necesidad de estudiar las funciones ministeriales descritas en el Nuevo Testamento. Un rasgo distintivo de los ministerios cristianos es que decían estar infundidos por el Espíritu Santo. Los profetas, los apóstoles y los doctores son algunas de las figuras autorizadas para predicar por estar inflamados del Espíritu. Como en el sacerdocio judío de esa época no se encontraban funciones semejantes, el autor infiere que debían de ser ministerios laicos. Después, Penna analiza la figura del epískopos. Con menciones de la literatura griega, el autor asevera que los "obispos", en el mundo griego, no eran sino delegados administrativos. Por tanto, el ministerio episcopal tuvo que ser igualmente profano.

Un efecto muy parecido tiene el análisis de las figuras de los diáconos, los presbíteros, los maestros, los evangelistas y los pastores que son mencionados en las Epístolas de Pablo. Todas estas funciones, por el solo hecho de estar ausentes de la literatura judía sacerdotal, resultan ser profanas y, por tanto, laicas. Penna nota, sin embargo, que los ministerios empiezan a cobrar un tono más institucional en los libros del Nuevo Testamento cuya composición es tardía: las Epístolas deuteropaulinas, la Epístola a los Hebreos, las Epístolas Pastorales y el Apocalipsis. Penna responderá, ante este desafío a su tesis, que la institucionalización de los ministerios surgió de la necesidad de monitorear las pretensiones de inspiración del Espíritu Santo que iban surgiendo conforme se extendía el cristianismo (pp. 91-92). La institucionalización sería una consecuencia circunstancial, ajena a los orígenes.

\footnotetext{
1 "Rom 1,7; 8,2.7; 12.,13; 15,2.5.2.6.31; 16,2..15; 1 Cor 1,2.; 6,1.2.; 14,33; 16,1.15; 2.Cor 1,1; 8,4; 9,1.12.; 13,12.; Fil 1,1; 4,2.2.; 1Tes 3,13; Flm 5.7" (nota \#39, p. 129).
} 
Una evidencia acerca de la naturaleza laical del cristianismo que se considerará como incuestionable son los lugares de culto de las primeras comunidades. Como bien se sabe, los cristianos no acudían a un templo, ni a la sinagoga, sino a simples casas (las domus ecclesice). Penna señala un importante elemento lingüístico en las narraciones donde están presentes estas casas: el uso, en Hechos de los Apóstoles 8:3 y 20:20, "del sintagma griego kat'oikon" que quiere decir "literalmente 'casa por casa'". Esta construcción permite entender que los primeros cristianos tenían ya "otro lugar de encuentro, lejos de ser sacerdotal, que es la casa", que es "de hecho una pluralidad de casas [...], ¡con su dimensión laica de privacidad!" (p. 96).

Las reuniones cristianas, así, debieron de estar desprovistas por completo de un sentido sacerdotal, o ritual. Procede el autor a desentrañar la manera en que se celebraban estas reuniones. El prelado asegura que no había tal cosa como una Liturgia de la Palabra, ni tampoco una Liturgia Eucarística, como hoy acontece en las misas católicas (p. 106). En cambio, el autor afirma que se trataba, más bien, de sencillos encuentros fraternales. Ahí eran centrales la comida y la bebida. Pero también se elevaban plegarias y se leían extractos de la vida de Jesús. "Para los creyentes en Cristo, por tanto, lo importante no era tanto la mera práctica cultual, sino, más bien, una vida de comunión/agápica (cfr. Rom 13:8-10) realizada en el nombre de la fe (cfr. Gal 5:6)" (p. 110).

Penna termina su extenso tercer capítulo con una revisión del uso del vocablo de "laico" en la literatura exclusivamente cristiana. La primera vez que aparece el vocablo es en la Epístola a los Corintios de Clemente de Roma. En ese pasaje (40:2-5) se usa el vocablo laikós para hacer una división entre el Sumo Sacerdote, los sacerdotes y los levitas frente al pueblo (pp. 118-119). Clemente de Roma, entonces, sólo aludía al Pueblo de Israel cuando usaba el vocablo laikós. Sin embargo, la primera vez que se usa el término para designar a los miembros de la Iglesia no será sino hasta la segunda mitad del siglo II, en los escritos de Tertuliano (p. 121).

El último capítulo del libro se consagra a estudiar el "sacerdocio en el cristianismo de los comienzos". Se inicia revisando el sentido con que se usa el término "sacerdote" en los libros del Nuevo Testamento. Además de las imprecaciones contra los sacerdotes del Templo de Jerusalén, plasmadas en los Evangelios, se usa el término de un modo peculiar en la Epístola a los Hebreos. A diferencia del resto de los libros neotestamentarios, la Epístola a los Hebreos es la 


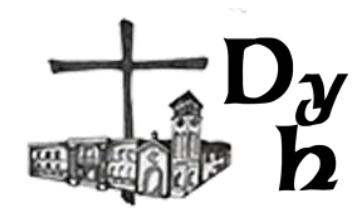

única que designa a Jesús como Sacerdote. Penna estudia la enigmática frase, de sobra conocida, donde se dice que Cristo es "Sumo Sacerdote según el orden de Melquisedec" (Hb 5:6). El autor dice que esto se refiere a que el sacerdocio de Jesús "no está basado en la descendencia levítica" (p. 163).

Así pues, el sacerdocio de Cristo se caracteriza por su procedencia no sacerdotal, lo cual, para Penna equivale a una procedencia laical. La indagación continúa hacia la cuestión del sacrificio del Cordero de Dios, y su significado para el sacerdocio laico del cristianismo. Cristo se dispone a sí mismo como ofrenda, con lo que vuelca cualquier régimen de sacrificios rituales. Con este acto Cristo ingresa "en el Santuario celeste (para ofrecer su propia sangre y sentarse a la derecha de Dios), con lo que supera el esquema levítico" (p. 170).

De la Primera Epístola de Pedro (1:4-5) y del Apocalipsis (1:6; 5:10; 20:6) Penna rescata algunos pasajes donde se dice que todos los creyentes son sacerdotes. La noción del sacerdocio universal de los cristianos, afirma el autor, nos lleva a pensar que las figuras de autoridad, los líderes de esas comunidades, sólo se distinguían por ejercer la labor pastoral (p. 180). De esa manera, Penna cree que cuando se usa un lenguaje sacerdotal (como en Rom 1:9; 15,15-16; Fil 2:17; o 2 Tim 4:6), se debe leer siempre en sentido metafórico (pp. 180, 183 y 189).

Romano Penna tiene que explicar, entonces, ciertos ritos que posteriormente configurarán al sacerdote cristiano: la imposición de las manos, el celibato y la vestimenta distintiva. La imposición de las manos - jeirotonía, en griego- es un acto heredado del Judaísmo. Penna se remite al libro de Números 27,18-23, donde Moisés impone sus manos sobre Josué para declararlo su legítimo sucesor. Sin embargo, Penna no encuentra que este rito se aplique para la ordenación de sacerdotes sino hasta el año 215, cuando se menciona en la Tradición Apostólica (p. 204). El autor dirá que este rito consumará, finalmente, la separación entre sacerdotes y laicos (p. 205). El celibato aparece por primera vez como un rasgo sacerdotal en las apologías de Tertuliano. Pero el pasaje sólo menciona una división entre los sacerdotes monógamos y los célibes. Será en el Concilio de Elvira, en el año 306, donde se estatuya que los obispos, los presbíteros y los diáconos no han de tener hijos ( $p$. 206). La cuestión de la vestimenta sacerdotal cierra el último capítulo. No hay, al 


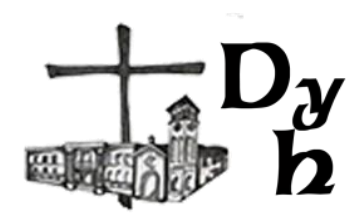

parecer, normas sobre esta cuestión antes del siglo V. Penna cree que el origen de la vestimenta sacerdotal tiene que ver con prohibiciones de que los sacerdotes vistieran como los bárbaros (p. 208).

La tesis del libro queda clara por la insistencia con que se repite en cada uno de los apartados del libro. Para Monseñor Penna, el origen del cristianismo tenía una naturaleza totalmente laical. La institución sacerdotal es, en consecuencia, una invención posterior. La tesis, en realidad, no abriga ninguna complejidad. No ofrece, tampoco, nueva documentación que nutra, o desafíe, el conocimiento sobre el cristianismo primitivo. Pero el libro tampoco parece proponerse eso. A través de la distinción entre laicos y sacerdotes, Monseñor Penna intenta proponer un nuevo ángulo de observación. Llegados a este punto, parece oportuno preguntarnos si se alcanzó el cometido. ¿La distinción de laicos y sacerdotes es operativa cuando se observa el cristianismo primitivo?

En primer lugar, hay que decir que el estudio presenta una debilidad de actualidad. El enfoque de este estudio es severamente anticuado. El autor sigue la vieja metodología de inicios del siglo XX de la -así llamada- Historia de las Religiones (Religionsgeschichtliche Schule). La premisa que guiaba esa escuela era que el cristianismo era una religión del mundo Mediterráneo. Por eso, se "insistía en que los estudiantes del N[uevo] T[estamento] debían conocer a Séneca, Epicteto, Plutarco, Luciano, Musonio Rufo, Marco Aurelio, Cicerón y los textos estoicos" (Trebolle, 1998: 30).

La Escuela de la Historia de las Religiones perdió considerable vitalidad tras el hallazgo de los Rollos del Mar Muerto. La nueva evidencia obligó a los estudiosos del cristianismo primitivo a insertarlo en su circunstancia más inmediata. Es decir, había que aprender a ver el cristianismo como parte del Judaísmo del Segundo Templo. Cosas que antes se consideraban como innovaciones cristianas, con la nueva evidencia pudieron ser insertadas en la compleja circunstancia judaica.

Sin embargo, los Rollos del Mar Muerto, y la cultura material del área, están lamentablemente ausentes en Un solo cuerpo. A veces se empalma uno que otro fragmento encontrado en las Cuevas de Qumrán, pero es claramente insuficiente. Al contrario, proliferan en exceso las citas de Heródoto, Platón, Juvenal, Diógenes Laercio, Tito Livio, entre muchos otros griegos y romanos. La omisión de los Rollos del Mar Muerto debilita el estudio, y confirma la antigüedad de su método. Los 


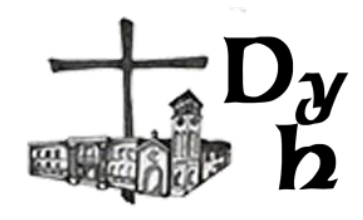

historiadores que usaron la Historia de las Religiones para estudiar el cristianismo primitivo no contaban con la nutrida evidencia que hoy hay sobre el Judaísmo del Segundo Templo. Penna, sin embargo, escribe desde el 2020, cuando esta evidencia documental tiene ya una tradición que está cerca de cumplir un siglo.

Este método anticuado explica con elocuencia por qué Romano Penna cree que sus anacronismos tienen congruencia. Si se toma al cristianismo como una "fe" del inabarcable mundo mediterráneo, desde luego aparecerá como un fenómeno extrañísimo, lleno de peculiaridades que van a contracorriente. Esto se debe a que, por "mundo mediterráneo", se estaría entendiendo, más bien, la cultura de sus gobernantes: el helenismo de los ptolomeos, los seléucidas y los romanos. De manera que intentar encajar la "fe" cristiana en la cultura helenizada tendría un solo efecto: se vería a Jesús de Nazaret y a sus seguidores como una contestación, casi disidente, del orden hegemónico de esa región helenizada. Pero ese procedimiento es tan falible como querer explicar la cultura birmana del siglo XIX desde el Imperio británico, o como querer integrar la Revolución Islámica de 1979 al interior del bloque de disidencias anticapitalistas de la Guerra Fría.

$\mathrm{Si}$, en cambio, se toma al cristianismo desde la circunstancia plenamente judía, entonces la figura de Jesús y el conjunto de sus seguidores se vuelven perfectamente explicables. Los Rollos del Mar Muerto han comprobado que muchos de los conceptos del Nuevo Testamento eran bien conocidos entre los judíos desde el siglo II a.C. (Kugel, 1997). El mesianismo, la escatología apocalíptica, las críticas contra los saduceos, contra los sacerdotes, contra la dinastía herodiana y la recuperación de la autenticidad del Pueblo de Israel son problemas constantes entre los judíos de la época. ¿Acaso también es legítimo membretar de "laicos" a los fariseos? ¿Eran laicos también los ex-sacerdotes que se exiliaron para conformar la Comunidad de Qumrán? ¿Y los samaritanos que, obedeciendo su propia Torá, se oponían al Templo de Jerusalén? ¿O los líderes de las comunidades de la Diáspora quienes, por estar lejos del Templo, no eran sacerdotes? Romano Penna, quizás, respondería que sí, que todos ellos igualmente eran laicos. De ser el caso, entonces la presunta laicidad de Jesús perdería la importancia que Un solo cuerpo le atribuye. 
Si Penna no se hubiera empecinado en los anacronismos, y se hubiera atenido a conceptos más justos con la cosmovisión del Judaísmo del Segundo Templo², tal vez habría ofrecido una visión distinta de los primeros cristianos. ¿A qué conceptos me refiero? A los que el mismo Penna planteaba en su primer capítulo: la imperante distinción judaica entre la pureza y la impureza. Ese sistema de dos términos opuestos fecundó un universo judío con toda una clasificación compleja que no debe ser ignorada.

Por usar algunos ejemplos: Penna mencionaba a los sacerdotes y a los levitas. Ambas clases pertenecen a la tribu de Leví, la tribu de sacerdotes. Aquí empieza a manifestarse el hecho de que hay tribus más puras que otras. Pero, como reseñé antes, los sacerdotes tenían más prerrogativas en el santuario que los levitas. Los sacerdotes eran descendientes del hermano de Moisés, Aarón. De manera que los aarónidas tenían un grado de pureza más elevado que los levitas. Aquí se nota una compleja red de requisitos de pureza al interior de una sola tribu. Considérese que eran doce las tribus.

Y, así como había distintas naturalezas de pureza y de impureza entre sacerdotes, las había entre otras clases de poblaciones judías. No era lo mismo un pescador de Galilea que no seguía las prescripciones de pureza que una mujer samaritana que, acaso, sí las cumpliera. Aquél seguía siendo más puro que ella, según el orden judío. O también valdría la pena determinar qué distinguía la impureza de un ciego de nacimiento frente a la impureza de un leproso. O bien, habría que definir qué diferencia había entre la impureza de una mujer acusada por los varones de adulterio frente a la impureza de un judío poseído por demonios. Ni se mencione la pureza de la endogamia y la exogamia, tal y como se daban en ese entrecruce de culturas y etnias disonantes como lo fue la región de la Tetrarquía Herodiana.

No se olvide que, además, hubo también nuevas propuestas para redefinir la pureza y la impureza en ese siglo I d.C. Los judíos de la Comunidad de Qumrán abandonaron las instituciones judías para habitar en el Desierto de Judea, donde

\footnotetext{
${ }^{2}$ Desde luego, no hubo una única cosmovisión del Judaísmo del Segundo Templo. Incluso hay matices en esta época. El primer Judaísmo del Segundo Templo, conformado por los que retornaban del exilio, es del todo distinto del Judaísmo del Segundo Templo de los Macabeos, y éste fue diferente de cuando el idumeo Herodes gobernó (Grabbe, 2010). Mantengo la categoría, primero, por simplificar, y, segundo, porque, a la postre, es más operativo tratar como "cultura hegemónica" monolítica al Judaísmo del Segundo Templo que al universo helenizado.
} 


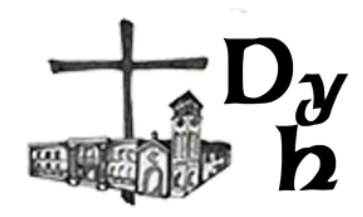

asumieron un régimen de pureza más estricto. Según la visión de estos hombres, todos los demás judíos habían traicionado la Ley, y sólo ellos preservaban al verdadero Israel.

Sirvan esos escasos ejemplos para corroborar la complejidad de lo puro y de lo impuro. Ése era el universo judaico al que pertenecía Jesús, y del que emana, en última instancia, el cristianismo. Los primeros cristianos eran, por encima de cualquier cosa, judeocristianos. Su identidad no estaba sometida a una fácil distinción entre sacerdotes y laicos. ¿No habría sido más estimulante estudiar, con rigor histórico, la pureza y la impureza de Jesús y sus seguidores?

No, Jesús el galileo no puede aislarse de su ingénito judaísmo en nombre de una inexistente "laicidad". Esa idea alcanza un punto insostenible cuando Romano Penna postula que Jesús fue, para los cristianos, una "alternativa para la Ley" judía, la Torá (p. 112). Así, Penna afirma que Jesús representaba una opción laical para liberar a los cristianos de las ataduras "moralístico-religiosas" de la Torá. Para sostener esta idea, Penna cita la Epístola a los Gálatas 2:21, donde Pablo dice que "si por la ley se obtuviera la justicia, habría muerto en vano Cristo". De manera que Jesús no sólo nada más habría sido un laico por su absoluta lejanía de la institución sacerdotal, sino que también suprimía la Torá, la Revelación misma de Dios. Romano Penna construye un Jesús que parece ni siquiera ser judío.

Hace algunos años, un lúcido exégeta de Pablo, Matthew W. Bates (2012), analizó "la hermenéutica de la proclamación apostólica". Bates notó que Pablo no predicó la anulación de la Torá en nombre de Cristo. Al contrario, Pablo viajó por las comunidades de cristianos, en las costas orientales del Mediterráneo, proclamando que la Torá fue verificada por Cristo. Pablo pronunció públicamente la buena noticia de que, lo que Dios reveló en las Escrituras, había sido cumplido. La vida, la pasión, la muerte y la resurrección de Cristo dieron cumplimiento a la Torá. De tal manera que, si los primeros cristianos pudieron creer en Cristo, fue porque eran judíos. Porque ellos vieron verificada la Torá, porque se convencieron de que las promesas de Dios se cumplieron, por eso se identificaron como seguidores de Cristo.

Pero, entonces, ¿qué pasa con aquella cita de Gálatas que transcribe Penna para sustentar su postura? Según Penna, el extracto de Ga 2:21 es una prueba para la superación de la Torá. Matthew Bates (2012: 120), sin embargo, echa un vistazo al 
resto del texto y encuentra exactamente lo contrario. Bates alcanza a ver que, en su locución, Pablo no va en contra de la Torá, sino que, de hecho, la usa como prueba para suscitar la fe en Cristo entre los creyentes de Galacia:

Así, Abrahán creyó en Dios y le fue reputado como justicia [Gn 15:6]. Tened, pues, entendido que los que creen, ésos son los hijos de Abrahán. La Escritura, previendo que Dios justificaría a los gentiles por la fe, anunció con antelación a Abrahán esta buena nueva: En ti serán bendecidas todas las naciones [Gn 12:3]. Así pues, los que creen son bendecidos con Abrahán el creyente.

Porque todos los que viven de las obras de la ley incurren en maldición. Pues dice la Escritura: Maldito todo el que no se mantenga en la práctica de todos los preceptos escritos en el libro de la Ley [Dt 27:26]. Y que la ley no justifica a nadie ante Dios es cosa evidente, pues el justo vivirá por la fe [Ha 2:4]; pero la ley no procede de la fe, antes bien quien practique sus preceptos, vivirá por ellos [Lv 18:5](Ga 3:6-11).

Se ve, entonces, cómo Pablo utiliza palabras de la Torá (Génesis, Levítico y Deuteronomio) para que los creyentes obren según el Espíritu. Jesús no fue ninguna alternativa a la Torá. Por eso, Pablo en la Epístola a los Romanos 3:31 dice: "Entonces ¿por la fe privamos a la ley de su valor? ¡De ningún modo! Más bien, la consolidamos". ¿No está esto en flagrante contradicción con la aseveración de Penna de que "la perspectiva de Pablo es que ni la Ley (ya sea natural, mosaica o civil), ni el poder político forman parte del euaggélion" (p. 118)?

La estrecha relación de Pablo con las Escrituras judías, ¿no nos habla de una pertenencia absoluta al Judaísmo, aun cuando predica también a los no judíos? ¿Estamos hablando, todavía, de "laicos? Si Romano Penna hubiera considerado la cultura material, habría encontrado que entre los códices cristianos de los siglos II y III la presencia de la Biblia Hebrea es avasalladora, aun por encima de los libros del Nuevo Testamento (Hurtado, 2006: 19-20). Esto es indicio de que las "Sagradas Escrituras" seguían siendo los libros de la Biblia Hebrea. Penna parece olvidar que el Nuevo Testamento no llegó a ser Sagrada Escritura sino hasta bien entrado el siglo II. Por eso, Joseph Ratzinger (1965: 56) afirmó que antes "de que el Nuevo Testamento mismo venga a ser Escritura, es fe que interpreta la «Escritura» (es decir, el Antiguo Testamento)". 


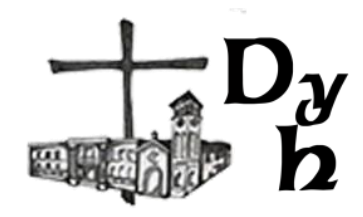

En efecto, Jesús, sus seguidores, Pablo y los primeros cristianos venían de una matriz judía, y por eso cobró sentido la fe en Cristo. La separación pronunciada que perpetra Penna entre el cristianismo primitivo y el Judaísmo del Segundo Templo es una ficción. Incluso esa idea de que el Sacerdocio de Cristo, según el orden de Melquisedec, era un sacerdocio laico es falsa. El custodio del archivo de los Rollos del Mar Muerto, Adolfo Roitman (2017), ya demostró que el Sacerdocio de Cristo, descrito en la Epístola a los Hebreos, está en perfecta continuidad con el Judaísmo del Segundo Templo. Roitman pudo demostrar esto porque analizó el fragmento 11QMelquisedec (11Q13), donde se representa a Melquisedec como un ser celestial. Roitman compara otra evidencia, como el libro de los Jubileos, y determina que Melquisedec era visto, en el Judaísmo del Segundo Templo, como "libertador", "sacerdote" y "juez escatológico" (Roitman, 2017: 213). Difícilmente estamos ante la presencia de un sacerdocio laico.

Por todo lo anterior, es inoperativa la distinción anacrónica de Penna. Para terminar, estableceré una última objeción referente al concepto mismo de "laico". Ya describí cómo dicho concepto no es operativo para hacer una observación del cristianismo primitivo. Quisiera ensayar ahora la respuesta al porqué. Es cierto que el vocablo "laico" encuentra su remoto origen —su étymon- en el sustantivo griego laikós. Pero no es cierto que nuestro concepto de "laico", tal y como lo entendemos en el siglo XXI, se remonte al concepto griego de laikós.

Hablar de laicos, hoy, presupone muchos aspectos ajenos al mundo judeocristiano. Penna lo dijo muy bien: el sustantivo "laico" está saturado de la cosmovisión secularizada y moderna. Esto es así porque "laico" es, ante todo, un concepto moderno. Utilizar el concepto de "laico" para imponerlo a Jesús el galileo, y a sus seguidores, no sólo provoca la inercia que toda incompatibilidad conlleva. Lo que también sucede con ese anacronismo es que se cancela la singularidad histórica del fenómeno judeocristiano.

Me explico mejor: el concepto actual de "laico" fue construido en la Modernidad, cuando toda forma religiosa pretendía ser liquidada ${ }^{3}$ por obstaculizar la

\footnotetext{
${ }^{3}$ Uso este verbo en armonía con una afirmación de Jürgen Habermas (2006:151): "las tradiciones religiosas parecen seguir siendo actuales incluso de una manera más intensa que la metafísica. Sería irrazonable descartar a priori la idea de que las religiones mundiales [...] mantienen con firmeza un
} 
libertad individual de los ciudadanos. "Este término, con la descristianización emprendida por los revolucionarios de 1790-1793, se volvió un sinónimo de una sociedad que no hacía ya más referencia a los conceptos cristianos". Así, por ejemplo, los "Cahiers de doléances ${ }^{4}$ de los Estados Generales de 1789 proponían que la enseñanza y la educación no fueran confiadas más a las órdenes eclesiásticas, sino a los padres de familia laicos" (Moatti, 2004: 85). Así pues, la referencia a la "laicidad" adquirió una función negadora de la religión. El propósito de liquidar la religión llevó a reinventar el concepto mismo de religión ${ }^{5}$.

Los modernos, desde sus predecesores, los deístas, hasta los ateos materialistas, forjaron un concepto de "religión" que fuera compatible con la esfera privada y con la intimidad de los ciudadanos. Sólo esa compatibilidad permitiría justificar la irrelevancia de la religión en los asuntos públicos del Estado. Por eso, el concepto moderno de "religión" tiene el efecto de encajonar en un espacio muy reducido fenómenos tan descomunales como lo son todas las tradiciones religiosas del mundo. De ahí que, en realidad, el término "religión" suela ser estéril a la hora de describir las particularidades, por ejemplo, del Islam, o del Budismo (y, si se mira con cuidado, sucede así también con el Cristianismo). Lo laico y lo secular, en la Cristiandad, siempre designaron lo temporal, lo pasajero, lo profano. Los modernos rescatarán esos conceptos para describir el Nuevo Tiempo (Neuzeit) emancipado del yugo de la religión. Así pues, la "laicidad" se transformó en un concepto antirreligioso. No es casual que el papa Pío IX haya condenado la laicización de la educación en el Sílabo de Errores.

Es, francamente, sorprendente que al autor de este libro le pase desapercibida la naturaleza antirreligiosa de la "laicidad" moderna. Lo es porque su primer capítulo se compone de un nutrido y fatigoso aparato crítico de perspicaces estudios sobre la secularización que exponen lo que acabo de describir. Uno de los libros citados es $E l$ desencantamiento del mundo (Gauchet, 2005) cuyo último capítulo, "Lo religioso

\footnotetext{
espacio dentro del edificio diferenciado de la modernidad porque su sustancia cognitiva todavía no ha sido liquidada" (las cursivas son del original).

${ }^{4}$ Literalmente: Cuadernos de Quejas. Se trata de documentos donde cada Estado compilaba peticiones y quejas para discutirse en las asambleas.

${ }^{5}$ Un promotor de esta idea explica que "es más fácil encontrar los orígenes del concepto moderno de religión en la llustración europea, y en su reacción contra hacia ella [la religión], pues fue la llustración la que marcó la emergencia de la cultura moderna europea de desapego y de reflexión de las creencias y las prácticas religiosas establecidas y heredadas" (Byrne, 1989: xi).
} 


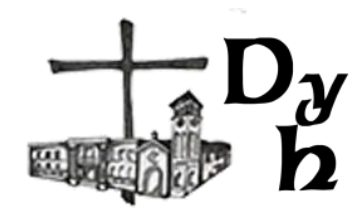

después de la religión", transparenta cómo mutó la experiencia religiosa después de la liquidación de la religión. También cita a Gianni Vattimo, quien es conocido, entre otras cosas, por caracterizar la Modernidad como un tiempo que humilla a la religión (Vattimo, 2004).

En consecuencia, Romano Penna usa anacronismos modernos, creados para limitar al extremo la influencia de las Iglesias cristianas, para describir el surgimiento del cristianismo. Penna advierte en una parte de su estudio que no hay que usar esta clase de conceptos, pues "son categorías modernas, además, acuñadas con una intención polémica anticristiana" (p. 180). Por eso aseveré que toda esta empresa termina por cancelar la complejidad religiosa.

Parece que, en última instancia, el obispo Penna elaboró su escrito con la noble intención de elevar, en nuestros días, la importancia de los laicos. Es claro que Penna respalda las felices denuncias que el papa Francisco ha lanzado en contra de "la enfermedad" del clericalismo. La demostración (en este caso, mal lograda) de que todo era laico entre los "primeros cristianos" sería útil para mermar esa enfermedad.

Desde la Reforma Protestante, los cristianos tienen que invocar aquellos tiempos "primitivos" para determinar qué sí y qué no es verdadero en su confesión cristiana. Los reformadores comprobaban con esta invocación que el "pseudocristianismo papista" se había desviado, en el transcurso de la historia, del verdadero cristianismo.

Sin embargo, un siglo después de la Reforma Protestante, algunos intelectuales europeos usaron esa misma invocación a los "tiempos primitivos" para comprobar que el cristianismo, a su vez, había tergiversado la "religión natural" de la Humanidad. Estos intelectuales hoy son catalogados bajo el nombre de deístas. Ellos crearon la idea de que Dios es absolutamente racional, por lo que la creencia en Él ha de ser racional. Así pues, la "religión revelada" apareció como un artificio atroz que había vuelto irracionales a los humanos. La propuesta de estos deístas, desde luego, culminó en la llustración.

Los intelectuales del siglo XVIII compartirán la idea deísta sobre el cristianismo. Serán ellos quienes demuestren que la fuente de donde brota la "religión revelada" -la Biblia - es irracional. La manera de hacer esa demostración consistió en un profundo conocimiento de las "antiguas lenguas orientales". Los ilustrados construyen el método de exégesis histórica de la Biblia (Legaspi, 2010). Así, la Biblia 
deja de ser la Sagrada Escritura y pasa a ser un libro histórico. Tanto las Iglesias reformadas como el catolicismo romano condenaron la investigación histórica, por profanar las Escrituras. Resultaba del todo peligrosa la reconstrucción histórica de los tiempos de Jesús, el judío galileo del siglo I.

Hoy, sin embargo, entre católicos tanto como entre protestantes, la teología parece requerir de los hallazgos históricos de la Biblia. Aparentemente, se ha reconciliado la relativización profana de la Biblia con las afirmaciones sobre el Dios revelado y encarnado. $\mathrm{Y}$ digo aparentemente porque los resultados tienden a ser semejantes a los que Penna presenta. Es decir, no se presenta la circunstancia histórica de aquel siglo I d.C., tan distante y ajena a la nuestra. En cambio, la historia usada para los fines actuales parece hacer muchas concesiones. No es inusual encontrar que un exégeta católico presente al cristianismo primitivo con rasgos muy semejantes a su confesión, y lo propio sucede entre exégetas protestantes. Pero una indagación histórica que salve las distancias verá, que, efectivamente, aquellos tiempos no tenían nada que ver con nuestros tiempos.

Tal vez Penna habría ofrecido un escrito más congruente si hubiera hecho otra clase de reflexión y no, más bien, historia. Recientemente, Enrique Dussel (2016: 105171) presentó una extravagante interpretación de la "justificación por la fe" de la Epístola a los Romanos. Desde el inicio, Dussel deja claro que su lectura es "simbólica". Esa advertencia nos permite a los lectores no esperar mucho rigor por parte del autor. Y, efectivamente, el lector encuentra que Dussel perturba por completo el sentido del concepto paulino de "fe". Para el académico liberacionista, la "fe" no es otra cosa sino el "consenso crítico intersubjetivo", al que llega "el pueblo" para oponerse a la Ley (Dussel, 2016: 156). Desde luego, semejante lectura no puede alcanzarse con una exégesis crítica e histórica. Pero Dussel no quiere eso -aunque transcriba vocablos griegos y hebreos como para dar contenido a sus opinionesRomano Penna, en cambio, sí lo pretende, pues diseña todo su escrito a partir de métodos rigurosamente históricos. Por eso, en realidad, el libro es una inmensa contradicción.

Los anacronismos son inevitables en la escritura de la historia. Es ingenuo evitarlo. Sin embargo, es prueba de un pensamiento sutil que un concepto vigente en el siglo XXI sea usado en un estudio histórico de tal manera que revele ángulos de observación antes insospechados. Pero, ¿cómo hacerlo? Habría que considerar lo 


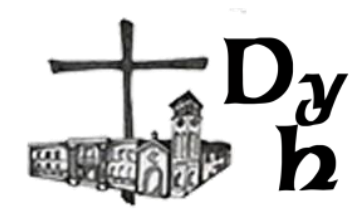

siguiente: "Lo que hace histórico a un objeto $-\mathrm{y}$ no veo otra forma de alcanzar la historización-", dice Hans Ulrich Gumbrecht, "es la disposición del observador para superar la inercia primaria de suponer que sabe lo suficiente como para hacer buen uso, o al menos un uso adecuado, de los objetos que encuentra" (Gumbrecht, 2007: 71). Tal vez por eso sentenció José Ortega y Gasset:

Tenemos con nuestra vida que entender las ajenas precisamente en lo que tienen de distintas y extrañas a la nuestra. Nuestra vida es el intérprete universal. Y la historia en cuanto disciplina intelectual es el esfuerzo metódico para hacer de todo ser humano un alter ego, donde ambos términos —el ego y el alter - han de tomarse en plena eficacia (Ortega y Gasset, 1964: 385).

\section{Bibliografía}

Byrne, P. (1989). Natural Religion and the Nature of Religion: The Legacy of Deism. Oxon: Routledge.

De Certeau, M. (2016). L'écriture de I'histoire. Paris: Gallimard.

Dussel, E. (2016). Filosofías del Sur: Descolonización y Transmodernidad (1era Reimpr.). Ciudad de México: Akal.

Gauchet, M. (2005). El desencantamiento del mundo: Una historia política de la religión. Madrid: Trotta.

Grabbe, L. L. (2010), An Introduction to Second Temple Judaism: History and Religion of the Jews in the Time of Nehemiah, the Maccabees, Hillel and Jesus. New York: T\&T Clark.

Gumbrecht, H. U. (2007) Los poderes de la filología. Dinámicas de una práctica académica del texto. Ciudad de México: Universidad Iberoamericana.

Habermas, J. (2006). Entre naturalismo y religión. Barcelona: Paidós.

Hurtado, L. W. (2006). The Earliest Christian Artifacts: Manuscripts and Christian Origins. Grand Rapids: Eerdmans.

Kugel, J. (1997), Traditions of the Bible: A Guide to the Bible as it was at the Start of the Common Era. Cambridge, MA: Harvard University Press.

Legaspi, M. C. (2010). The Death of Scripture and the Rise of Biblical Studies. Oxforx: Oxford University Press. 


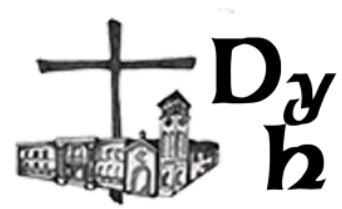

Moatti, D. (2004), La laïcité ou I'histoire mouvementée d'un concept français. Pyramides. 8. 83-98.

Ortega y Gasset, J. (1964). Obras Completas. Tomo VI (1941-1946) y Brindis y Prólogos (6ta ed., 377-418). Madrid: Revista de Occidente.

Ratzinger, J. (1965). Primado, episcopado y "Successio Apostolica". En: Rahner, K. y Ratzinger, J. Episcopado y primado (3a reimpr., 43-59). Barcelona: Herder.

Roitman, A. D. (2017). El misterio de Melquisedec en el cristianismo antiguo a la luz de los Rollos del Mar Muerto. Bandue. 10. 199-232.

Trebolle Barrera, J. (1998). The Jewish Bible and the Christian Bible: An Introduction to the History of the Bible. Leiden: Brill.

Vattimo, G. (2004). Creer que se cree. Barcelona: Paidós. 